\title{
IMPLEMENTAÇÃO DE POLÍTICA DE SEGURANÇA PÚBLICA: UMA ANÁLISE DO PROGRAMA PACTO PELA VIDA NA BAHIA
}

\author{
Maribel Fernandes Ribeiro Santana ${ }^{1}$ \\ Élvia Mirian Cavalcanti Fadul ${ }^{2}$
}

\section{RESUMO}

Este trabalho analisa os fatores condicionantes da implementação da Política Pública de Segurança no Estado da Bahia denominada Programa Pacto Pela Vida, modelo de gestão governamental transversal, focado na atuação integrada, na redução da violência e no modelo de Segurança Cidadã. O trabalho descreve os fatores que influenciaram o processo de implementação dessa política, o modelo de gestão e os aspectos institucionais, organizacionais e operativos. A base teórica apoia-se nas fases das políticas públicas, especialmente na implementação e na síntese dos modelos top-down e bottom-up. Na pesquisa qualitativa foi utilizado, como estratégia de investigação, o método do estudo de caso, desenvolvido através de questionários, entrevistas exploratórias e análise de conteúdo. As análises mostram que a implementação deste Programa apresentou resultados significativos na redução do número de homicídios e que o Estado consolidou um modelo de gestão que busca a eficiência para a melhoria da segurança pública e da prevenção social.

Palavras-chave: Políticas de Segurança Pública; Programa Pacto pela Vida; Gestão Governamental.

\footnotetext{
${ }^{1}$ Doutoranda em Administração (UFBA), Mestre em Administração (UNIFACS), Especialista em Gestão de Projetos (UNIFACS), Segurança contra Incêndio e Pânico e Defesa Civil (IFBA/ABM) Bacharel em Segurança Pública e Administração (UNEB) e Major do Corpo de Bombeiros Militar da Bahia. maribel.santana@ssp.ba.gov.br

${ }^{2}$ Pós-Doutorado realizado na École Nacionale de Ponts et Chaussées, França, no laboratório LEESU - Laboratoire Eau, Environnement et Systèmes Urbains, Doutora em Urbanismo pela UPEC - Université Paris-Est Créteil Val de Marne. Mestre em Administração pela Universidade Federal da Bahia (UFBA), Coordenadora do PPGA da UNIFACS. elvia@unifacs.br
} 


\title{
PUBLIC SECURITY POLICY: AN ANALYSIS OF THE 'PACTO PELA VIDA NA BAHIA' PROGRAM
}

\begin{abstract}
This paper analyzes the conditioning factors for the implementation of the Public Security Policy in the State of Bahia called Programa Pacto Pela Vida, a transversal government management model, focused on integrated action, on reducing violence and on the Citizen Security model. The work describes the factors that influenced the process of implementing this policy, the management model and the institutional, organizational and operational aspects. The theoretical basis is supported by the public policy phases, especially in the implementation and synthesis of the top-down and bottom-up models. In qualitative research, the case study method was used as an investigation strategy, developed through questionnaires, exploratory interviews and content analysis. The analyzes show that the implementation of this Program has shown significant results in reducing the number of homicides and that the State has consolidated a management model that seeks efficiency to improve public security and social prevention.
\end{abstract}

Keywords: Implementation of Public Policies. Government Management. Public Safety. 


\section{INTRODUÇÃO}

Este estudo visa analisar o processo de implementação da Política Pública de Segurança denominada Programa Pacto pela Vida (PPV) instituída no Estado da Bahia. No âmbito nacional, o Governo Federal procurou atuar e apoiar os Estados através do Programa Nacional de Segurança Pública com Cidadania PRONASCI, do Ministério de Justiça (BRASIL, 2007). No Estado de Pernambuco, em 2007, como desdobramento do PRONASCI, foi criado um modelo de gestão da Segurança Pública inovador e com foco nas ações de prevenção social, o Programa Pacto Pela Vida.

Apesar dos investimentos do PRONASCl e de uma redução dos índices criminais, segundo o Mapa da Violência no ano de 2007, o Brasil registrou 47.707 homicídios, destes 15.428 se concentraram na Região Nordeste. $O$ Estado do Pernambuco ocupou o primeiro lugar na região, com 4.560 homicídios, e a Bahia, com 3.619, ficou em segundo lugar no número de mortes violentas. Estes dados demonstram que uma mudança na política de segurança era imperiosa.

Nos anos seguintes, o Estado da Bahia, ao buscar boas práticas no âmbito nacional, por meio da Secretaria da Segurança Pública para construir o seu Plano Estadual de Segurança Pública - PLANESP 2012/2015, identificou o PPV de Pernambuco como um modelo positivo, pois ficou evidenciado que o Estado de Pernambuco, com a implementação do PPV, desde 2007, conseguiu, a cada ano, reduzir o número de mortes violentas, chegando a registrar, em 2011, 3.464 mortes, sendo o único Estado da Região Nordeste que registrou uma redução e alcançou $-25.2 \%$ no período estudado pelo mapa.

Considerando como prioridade o combate eficaz e eficiente aos Crimes Violentos Letais Intencionais - CVLI e consoante o Plano Estadual de Segurança Pública - PLANESP, o Governo do Estado da Bahia se propõe 


\section{Revista FLAMMAE}

Revista Científica do Corpo de Bombeiros Militar de Pernambuco

Artigo Publicado no Vol.06 N.17 - Edição Jul a Dez 2020 - ISSN 2359-4829

Versão on-line disponível em: http://www.revistaflammae.com

atender prioritariamente às principais necessidades institucionais e às demandas de segurança pública em comunidades identificadas como vulneráveis e em áreas de risco social. O PLANESP parte da premissa de que a implantação de um processo sustentável de um pacto pela vida e pela paz passa, essencialmente, pelo alinhamento das políticas sociais, com a transformação profunda das estruturas dos órgãos policiais, de retomada de valores fundamentais e de identidade institucional. É nesse contexto que este estudo se insere e busca identificar e analisar os fatores condicionantes que contribuíram para a modelagem do Programa Pacto pela Vida (PPV) enquanto política pública de segurança, cujo objetivo principal é reduzir os crimes contra a vida e o patrimônio no Estado da Bahia.

Para tanto, o artigo apresenta uma breve descrição do sistema de segurança pública e sua influência para a implementação da Política Pública de Segurança chamada Pacto Pela Vida. Utiliza, como ferramenta de análise, o processo de implementação de políticas públicas descrito pelos modelos topdown e bottom-up baseados no ciclo de política (policy cycle). Traz, em seguida, uma análise aprofundada dos fatores condicionantes, institucionais, organizacionais e operativos, observados na fase de implementação e estabelecimento dos indicadores do Programa na Bahia e, por fim, apresenta as suas conclusões.

\section{PROGRAMA PACTO PELA VIDA NO ESTADO DA BAHIA}

O Pacto Pela Vida é um Programa de Estado criado pela Lei $n^{\circ} 12.357$ de 26 de setembro de 2011, no âmbito do Sistema de Defesa Social - SDS, cujo objetivo principal é a promoção da paz social. Trata-se de uma nova política pública de segurança, construída de forma pactuada com a sociedade, articulada e integrada com o Poder Judiciário, a Assembleia Legislativa, o Ministério Público, a Defensoria Pública, os municípios e a União. (BAHIA, 


\section{Revista FLAMMAE}

Revista Científica do Corpo de Bombeiros Militar de Pernambuco

Artigo Publicado no Vol.06 N.17 - Edição Jul a Dez 2020 - ISSN 2359-4829

Versão on-line disponível em: http://www.revistaflammae.com

2011). O PPV tem como finalidade promover a redução da criminalidade e da violência no Estado da Bahia, seus principais indicadores de criminalidade são CVLI - Crimes Violentos Letais Intencionais: indicador composto por homicídio doloso, roubo seguido de morte e lesão corporal seguida de morte e o CVP Crimes Violentos contra o Patrimônio: indicador composto por extorsão mediante sequestro, roubo a ônibus, a casas comerciais, a residências, a transeuntes e a veículos.

Vale ressaltar que os recursos previstos para o Programa PPV na Bahia, no PPA 2012-2015, foram de $R \$ 11.388 .441 .000,00$ (onze bilhões, trezentos $e$ oitenta e oito milhões, quatrocentos e quarenta e um mil reais), tendo como indicadores prioritários do programa uma visão da preservação do bem maior, que é a vida, tendo como principal indicador do programa a redução dos crimes contra a vida - CVLI. O modelo de gestão do PPV visa ampliar a participação nas ações sociais, colaborar na vigilância natural e no âmbito da manutenção da política, avaliar as ações até o ano de 2015 e, assim, obter um extrato do cenário em que se constate o êxito da política e as correções efetuadas no curso da sua implementação.

O programa possui um novo modelo de gestão, com a criação de diversas instâncias que se relacionam: um Comitê de Governança, integrado pelos dirigentes máximos dos Poderes e Instituições do Estado, responsável pela definição das diretrizes estratégicas e pelo acompanhamento das ações; um Comitê Executivo, presidido pelo Governador e integrado por representantes dos Poderes e Instituições do Estado, com a finalidade de promover a articulação entre os processos de formulação, implantação, monitoramento e avaliação de suas ações; cinco Câmaras Setoriais para propor e definir diretrizes e políticas setoriais que contribuam para a redução das taxas de Crimes Violentos Letais Intencionais - CVLI.

O Núcleo de Gestão, que é uma unidade de monitoramento e avaliação dos resultados do programa, também foi pensado em um formato de atuação no território, de forma técnica, sendo elaborada uma distribuição, para fins de 


\section{Revista FLAMMAE}

Revista Científica do Corpo de Bombeiros Militar de Pernambuco

Artigo Publicado no Vol.06 N.17 - Edição Jul a Dez 2020 - ISSN 2359-4829

Versão on-line disponível em: http://www.revistaflammae.com

execução e monitoramento das ações do programa e para a aferição dos indicadores: a criação de Regiões Integradas de Segurança Pública - RISP, compostas por Áreas Integradas de Segurança Pública - AISP, dentro do território do Estado da Bahia.

No âmbito das ações desenvolvidas, destacam-se as ações policiais integradas pelas unidades que compõem o sistema de segurança pública com: intensificação da repressão qualificada, mediante o uso da inteligência policial; ações policiais preventivas, mediante a aproximação da polícia com a comunidade; implantação de Bases Comunitárias de Segurança Pública BCS, que são estruturas físicas em áreas consideradas críticas em termos de criminalidade violenta, funcionando como instrumento de polícia comunitária. Aproximam a polícia dos moradores e aumentam a sensação de segurança nessas áreas. Além da ativa participação social como beneficiária da política pública nas áreas críticas para que a política alcance os objetivos, outro fator que se destaca é a liderança do Chefe do Poder Executivo na condução do processo de elaboração e implementação da política pública.

\section{IMPLEMENTAÇÃO DE POLÍTICAS PÚBLICAS}

Conhecer como as políticas públicas são formuladas (policy making) e o seu processo de implementação é um desafio. Tomando como ponto de partida a sistematização das ações governamentais baseadas no ciclo de política (policy cycle) para o desenho do processo de implementação que alcance os níveis de Governo - Federal, Estadual e Municipal - e ainda incremente uma real capacidade de articulação dos atores governamentais encarregados desse processo, essa é a chave desta pesquisa sobre a implementação do Programa Pacto Pela Vida na Bahia.

No processo de implementação de uma política pública destacam-se duas vertentes: top-down e bottom-up. A vertente top-down ressalta que as ações de 


\section{Revista FLAMMAE}

Revista Científica do Corpo de Bombeiros Militar de Pernambuco

Artigo Publicado no Vol.06 N.17 - Edição Jul a Dez 2020 - ISSN 2359-4829

Versão on-line disponível em: http://www.revistaflammae.com

implementação de uma política pública coincidem com as decisões estabelecidas pelas autoridades que a formularam (MATLAND, 1995) e esse modelo foi o seguido para a implantação do Programa Pacto Pela Vida, na Bahia, partindo do nível estratégico e dos agentes governamentais como formuladores da política pública na área de segurança pública. Os teóricos da vertente bottom-up focam nos beneficiários das políticas públicas e nos agentes implementadores, argumentando que a política pública implementada se define no nível local.

Para Minas Gerais (2011) e também na obra de Dias e Matos (2012, p. 82-83), alguns aspectos críticos da fase de implementação associados às dimensões das políticas públicas são:

- Dimensão institucional: falta de clareza na definição de objetivos, metas e estratégias; inadequação na concepção da política, diversidade de atores envolvidos na execução da política; inexperiência dos atores com a estratégia de execução; e incompatibilidade técnica e política de gestão.

- Dimensão organizacional: excesso de burocracia; tarefas fragmentadas; departamentos desarticulados; ausência de informações confiáveis e precisas para monitorar a implementação; baixo grau de comunicação entre decisores e executores; ausência de profissionais especializados; inexistência ou baixo índice de incentivos para melhorar a gestão; falta de motivação dos funcionários; e rotatividade dos atores políticos.

- Dimensão ambiental: dificuldade de participação dos beneficiários da política; baixo nível de informação; influência e organização; distância entre os órgãos centrais de tomada de decisão e os executores da política.

\section{PROCEDIMENTOS METODOLÓGICOS}


A metodologia aplicada é essencialmente qualitativa, pelo método teórico, com base em pesquisa documental e em estudo do cenário. O estudo discute como tema central os fatores condicionantes da implementação da Política Pública de Segurança: o Programa Pacto Pela Vida, no Estado da Bahia. A Lei $n^{\circ}$ 12.357 que instituiu o Programa Pacto pela Vida relaciona as 13 secretarias de Estado e as 5 Câmaras Técnicas do PPV, tendo estas como ponto de partida foram encaminhados questionários de pesquisa a todas as secretarias e Câmaras Técnicas, entrevistados o atual Coordenador Executivo do programa e gestores envolvidos na implementação da política pública de segurança.

Os procedimentos metodológicos foram divididos em três etapas: na primeira etapa foi realizada uma pesquisa documental com o objetivo de analisar a legislação vigente da implementação do PPV e o PPA 2012/2015; a segunda etapa contou com a análise do relatório anual de governo; e a terceira etapa com a realização de entrevistas e a aplicação de questionários para compreender o processo de implementação dessa política pública.

No processo de investigação qualitativa sobre a fase de implementação foram realizadas entrevistas semi-estruturadas e a aplicação de questionários estruturados com gestores públicos e profissionais da Segurança Pública, responsáveis pela implementação do programa através das secretarias que pactuaram, buscando identificar os fatores condicionantes do processo de pactuação.

A revisão de literatura e uma análise de abordagens metodológicas descrevem que um bom modelo de gestão para resultados deve ser dinâmico, abrangente e multidimensional. Assim, os indicadores estabelecidos pelo Programa Pacto Pela Vida devem dar conta de toda a dimensão dos resultados propostos pela Política Pública de Segurança elaborada e em execução há quatro anos, sendo assim, como esses fatores são observados no modelo de análise com variáveis baseadas em Minas Gerais (2011) e Dias e Matos (2012): 
Revista Científica do Corpo de Bombeiros Militar de Pernambuco

Artigo Publicado no Vol.06 N.17 - Edição Jul a Dez 2020 - ISSN 2359-4829

Versão on-line disponível em: http://www.revistaflammae.com

- Fatores Institucionais: o processo de tomada de decisão e entrada na agenda de governo; a elaboração da lei e da estratégia de atuação; o envolvimento dos atores na estratégia de implementação e gestão orçamentária.

- Fatores Organizacionais: processo de gestão integrada do PPV; a atuação das câmaras técnicas; a rotatividade dos gestores públicos e a transversalidade nas ações no PPV.

- Fatores Operativos: o envolvimento da sociedade; a capacitação do público interno - endomarketing -; e o foco nas ações de prevenção social.

Através de um diagnóstico e análise, foi possível conhecer o cenário e o conjunto das características da Política Pública de Segurança implantada no Estado da Bahia, o monitoramento das ações desenvolvidas através da análise do cenário, buscando evidências da efetividade do indicador CVLI e o aumento da sensação de segurança, que são a chave para a gestão da segurança pública através do PPV.

\section{ANALISE E RESULTADOS}

Este capítulo destina-se a ampliar a compreensão sobre os processos de políticas públicas (policy processes) e contribuir para uma análise aprofundada dos fatores condicionantes - institucionais, organizacionais e operativos, observados na fase de implementação do Programa Pacto Pela Vida, na Bahia. Optou-se por analisar os Relatórios Anuais de Governo 2012, 2013 e 2014, pois já estavam consolidados e apresentam um cenário operativo das ações implementadas no âmbito do programa, bem como a real utilização do orçamento, os valores previstos e o que foi implementado. Foram, ainda, verificadas as respostas enviadas pelas secretarias e Câmaras Setoriais, 
Revista Científica do Corpo de Bombeiros Militar de Pernambuco

Artigo Publicado no Vol.06 N.17 - Edição Jul a Dez 2020 - ISSN 2359-4829

Versão on-line disponível em: http://www.revistaflammae.com

finalizando com as entrevistas, para dar suporte à aplicação dos fatores condicionantes: institucionais, organizacionais e operativos, conforme os resultados apresentados a seguir.

\subsection{Analise do Relatório Anual de Governo e Relatório de Avaliação da} Bahia-2012, 2013 e 2014

A Secretaria de Planejamento (SEPLAN) e a Secretaria da Fazenda da Bahia (SEFAZ-BA) relacionam as ações realizadas por programas e compromissos relativos a esta área temática para dar conta da execução orçamentária do PPV no Eixo de Inclusão Social e Afirmação de Direitos Humanos, na área temática: Segurança Pública e sendo o Programa no 105 - Pacto Pela Vida.

No ano de 2012, o primeiro ano de atividades do PPV na Bahia, teve previsto no PPA R $\$ 2.865 .551,12$ bilhões e foram executados $R \$ 2.782 .282,35$ bilhões do orçamento, observa-se que as três secretarias que foram envolvidas diretamente no programa foram a SSP-BA, com sete compromissos, SJCDH e a SEDES (BAHIA, 2012). No ano seguinte, foi divulgado o Relatório Anual de Governo de 2013 - Volume II (BAHIA, 2013), no qual se ressalta que o Governo do Estado destinou à política social uma expressiva participação no volume de recursos. No ano de 2013, o PPV na Bahia, teve previsto no PPA $R \$ 3.432 .168,00$ bilhões e foram executados $R \$ 3.131 .697,00$, ficam claros os fatores institucionais através do estabelecimento de uma gestão orçamentária específica do programa.

Quanto aos fatores organizacionais, é observado o direcionamento das ações através das Câmaras Setoriais do programa; no que se refere aos fatores operativos, estes estão diretamente relacionados com as ações de prevenção social, cabe ressaltar que as ações de prevenção ainda figuram com um número reduzido frente às ações desenvolvidas pela Segurança Pública e, 


\section{Revista FLAMMAE}

Revista Científica do Corpo de Bombeiros Militar de Pernambuco

Artigo Publicado no Vol.06 N.17 - Edição Jul a Dez 2020 - ISSN 2359-4829

Versão on-line disponível em: http://www.revistaflammae.com

apesar dos investimentos na repressão qualificada, é necessário que as demais secretarias envolvidas no pacto consigam realizar ações e contribuir para o alcance dos indicadores.

Em 2014, o recurso orçamentário previsto para o programa, orçado em $R \$$ 3.397.795.739,00 bilhões e liquidado $\mathrm{R} \$ 2.038 .777 .917,89$ bilhões, observa-se uma redução significativa no final da segunda gestão do governo Jaques Wagner, registrou-se nesse ano a inclusão da Secretaria da Educação (SEC), com uma ação no âmbito do PPV juntamente com a SEDES, SJCDH e SSP para cumprir os compromissos estabelecidos na PPA 2012/2015, conforme segue a descrição abaixo (BAHIA, 2014):

Diante dos Relatórios Anuais de Governo dos anos de 2012, 2013 e 2014, é possível concluir que o escopo do programa é demasiadamente amplo e os compromissos firmados no PPA 2012-2015 são insuficientes para alcançar o objetivo proposto e dar conta dos indicadores estabelecidos inicialmente, quando da modelagem do PPV na Bahia.

\subsection{Análise das ações das Secretarias de Governo e instâncias de governança}

A SEPROMI tem atuado com ações de prevenção social e é um forte articulador dos movimentos sociais, por tratar da igualdade racial, por dialogar com os movimentos negros, pelo entendimento de que a população negra, principalmente a juventude, é vulnerável às condições de insegurança, entendendo, assim, que existe um viés de racismo ainda a ser superado pela sociedade brasileira e baiana.

Para o entrevistado 1 o fator organizacional começa a consolidar um processo de gestão integrada e transversal em os atores governamentais e beneficiários da política pública pois conseguiu um arranjo institucional que permite a 


\section{Revista FLAMMAE}

Revista Científica do Corpo de Bombeiros Militar de Pernambuco

Artigo Publicado no Vol.06 N.17 - Edição Jul a Dez 2020 - ISSN 2359-4829

Versão on-line disponível em: http://www.revistaflammae.com

reunião de dez secretarias de Estado, com o Ministério Público, a Defensoria Pública, a Assembleia Legislativa, o Poder Judiciário e a sociedade organizada, para tratar de um tema tão delicado, incorporando a questão da cidadania no trato da segurança pública, definindo papéis transversais.

A Secretaria do Trabalho, Emprego, Renda e Esporte do Estado da Bahia (SETRE), apesar de envolvida formalmente e por lei no processo de implementação do Pacto, não relata essa experiência, pois a entrevistada 2 não participou do processo de tomada de decisão nem da elaboração da estratégia de atuação, mas um fator identificado negativamente foi a gestão orçamentária para o programa, pois acredita que os recursos financeiros disponibilizados não são suficientes para a realização de todas as ações do Programa PPV.

No caso da SETRE, o orçamento é utilizado integralmente nas ações de qualificação social e profissional, ofertadas através do Programa Qualifica Bahia - Pacto Pela Vida. No rol dos fatores operativos, a entrevistada 2 afirma que os servidores envolvidos na execução do programa conhecem os objetivos previstos, mas desconhece as ações de capacitação voltadas ao público interno. Sendo assim, a entrevistada sinaliza uma falha que pode comprometer os resultados, pois um dos fatores condicionantes no processo de implementação é a ativa participação dos atores executores.

A SJDHDS atua formalmente no PPV Bahia, o secretário está na pasta desde 2015 e também é responsável pela coordenação da Câmara Setorial de Prevenção Social e da Câmara Setorial de Enfrentamento ao Crack e outras Drogas, informa que não participou do processo de implementação. Sendo assim, o fator institucional de atuação na elaboração da estratégia de implementação não pode ser verificado, somente tendo respostas envolvendo os fatores organizacionais e operativos.

Quanto ao fator organizacional de implementação do programa destaca a atuação do Núcleo Gestor do Programa PPV no planejamento das reuniões do 


\section{Revista FLAMMAE}

Revista Científica do Corpo de Bombeiros Militar de Pernambuco

Artigo Publicado no Vol.06 N.17 - Edição Jul a Dez 2020 - ISSN 2359-4829

Versão on-line disponível em: http://www.revistaflammae.com

Comitê Executivo, acompanhamento das ações das Câmaras Setoriais, formulação de propostas para condução dos projetos e ações que são executados no âmbito do PPV, mas até o momento um estudo sobre os impactos do PPV na Bahia, mas com relação aos indicadores afirma que para a manutenção da política são necessários ajustes orçamentários e a criação de indicadores que reflitam os impactos das ações dos demais poderes e da área social.

A Secretaria da Segurança Pública da Bahia é uma das protagonistas na modelagem do Programa Pacto pela Vida (fator institucional) e a coordenadora da Câmara Setorial da Segurança Pública (fator organizacional), para o entrevistado 4 o ponto chave do programa é adotar o modelo de gestão por resultados, baseado no monitoramento do indicador estratégico e de indicadores de produtividade, com a identificação de áreas críticas, que passam a ser tratadas como prioritárias não apenas pela SSP, mas também pelas outras secretarias e poderes que integram o programa.

Quanto ao fator institucional de gestão orçamentária para a implementação do Programa PPV, afirma que os recursos disponibilizados foram utilizados para a contratação de policiais, equipamentos, capacitação e a implantação de novas unidades, como a Delegacia de Homicídios e Proteção à Pessoa e as Bases Comunitárias de Segurança e realizadas capacitações do público interno.

Porém, para a manutenção do programa é necessário construir indicadores também para as ações do Tribunal de Justiça da Bahia, da Defensoria Pública, entre outros atores que operam de forma transversal no Programa Pacto Pela Vida, na Bahia, caracterizando fatores organizacionais, afirma ser uma política pública exitosa, ele destaca especialmente a implantação das Bases Comunitárias de Segurança e redução de CVLI.

Uma das descrições mais ricas de todo o processo de implementação da Política Pública de Segurança é o relato do coordenador executivo do Programa Pacto pela Vida que, de forma bastante aprofundada, relatou a sua 


\section{Revista FLAMMAE}

Revista Científica do Corpo de Bombeiros Militar de Pernambuco

Artigo Publicado no Vol.06 N.17 - Edição Jul a Dez 2020 - ISSN 2359-4829

Versão on-line disponível em: http://www.revistaflammae.com

experiência na esfera de governo e na condução das ações do PPV e relata desde o processo de tomada de decisão e a entrada do tema na agenda de governo e a relevância na implementação do PPV.

O entrevistado 5 destaca que o orçamento destinado à realização das ações e a construção do planejamento plurianual ocorreu de maneira participativa e incorporando a demanda social. O coordenador executivo relaciona os desafios para o programa é rever os indicadores, ele remete aos resultados já alcançados e a exemplos de Áreas de Base Comunitárias com mais de um ano sem homicídios, como nas áreas do Bairro da Paz e do Calabar e uma redução de significativa de $25 \%$ no CVLI.

\section{CONCLUSÕES}

Pode-se concluir que os resultados obtidos pela pesquisa foram similares ao entendimento da literatura de implementação quando são analisados o ciclo das políticas públicas e os fatores condicionantes do processo de implementação, especialmente uma Política Pública de Segurança, que necessita de outras ações para sustentar a redução dos indicadores em longo prazo, e que falhas na implementação influenciam todo o ciclo da política.

A análise dos fatores institucionais, organizacionais e operativos, buscou dar conta do cenário das Políticas Públicas de Segurança e, em especial, o Programa Pacto Pela Vida, na Bahia. De forma geral, o programa foi considerado uma política pública exitosa pelos gestores entrevistados nesta pesquisa, o que foi ratificado quando analisados os resultados apresentados nos relatórios anuais de governo e na avaliação de indicadores, especialmente a significativa redução no indicador prioritário que é o número de CVLI.

O fator organizacional que envolve uma gestão integrada do programa, a atuação das câmaras setoriais e a transversalidade de ações foram os 
Revista Científica do Corpo de Bombeiros Militar de Pernambuco

Artigo Publicado no Vol.06 N.17 - Edição Jul a Dez 2020 - ISSN 2359-4829

Versão on-line disponível em: http://www.revistaflammae.com

destaques e figuram como fatores condicionantes para o sucesso na fase de implementação, sendo assim, a rotatividade dos atores governamentais influenciou essa implementação; atualmente, muitos atores não acompanharam o processo de tomada de decisão e elaboração da estratégia de atuação integrada.

O fator institucional, com os atores envolvidos na implementação do programa, a sua capacidade de execução das metas e do orçamento, bem como a definição de uma estratégia de atuação também foi amparada em um modelo top-down. Os governadores estiveram sempre diretamente envolvidos, tanto no processo de tomada de decisão para a implementação do programa em 2011, quanto no momento atual, mantendo o processo de gestão integrada.

Com relação ao fator operativo, muitos relatos afirmam que a modelagem do PPV permitiu uma interlocução dos atores e a realização de ações transversais, que podem ser monitoradas e avaliadas rotineiramente, como as ações descritas como mais eficientes são focadas na repressão qualificada dos crimes, as ações de prevenção social ainda necessitam uma estruturação e tempo para que possam alcançar resultados efetivos.

A participação social aparece fortemente com a realização de ações voltadas aos beneficiários da política pública, porém não foi relatada uma efetiva participação social na construção de novos caminhos, nem na avaliação das ações já executadas, nem mesmo seu papel nas Câmaras Setoriais como colaboradores no planejamento de ações para as áreas com altos índices de criminalidade; este é um dos desafios para ações corretivas no programa.

Um segundo momento para rever a estratégia de atuação e o envolvimento dos atores será o divisor de águas para que se possa ter um modelo flexível que se adapte à realidade local, construindo novos caminhos e corrigindo as falhas do curso da execução. Para continuidade da política é necessário que se aprimorem os instrumentos de monitoramento e os indicadores, permitindo uma sólida avaliação da política pública e, no futuro, permitindo que a 
Revista Científica do Corpo de Bombeiros Militar de Pernambuco

Artigo Publicado no Vol.06 N.17 - Edição Jul a Dez 2020 - ISSN 2359-4829

Versão on-line disponível em: http://www.revistaflammae.com

sociedade possa replicar modelos que conseguiram transformar o cenário e promover uma efetiva sensação de segurança ao cidadão.

\section{REFERÊNCIAS}

BAHIA. Pacto pela Vida: Plano Estadual de Segurança Pública. 2015.

BAHIA. Secretaria de Segurança Pública. Plano Estadual de Segurança Pública - PLANESP, Governo da Bahia 2012 a 2015. Salvador. 2011.

BAHIA. Relatório Anual de Avaliação Parcial da Execução do PPA 20122015. Salvador.

BAHIA. Relatório Anual de Governo 2012. Salvador. 2013.

BAHIA. Relatório Anual de Governo 2013. Salvador. 2014.

BAHIA. Relatório Anual de Governo 2014. Salvador. 2014.

BAHIA. Lei $\mathbf{n}^{\circ}$ 12.357, de 26 de setembro de 2011. Institui o Sistema de Defesa Social, o Programa Pacto pela Vida, e dá outras providências.

Salvador: Diário Oficial da Bahia, 2011.

BRASIL. MINISTÉRIO DA JUSTIÇA. Mapa da violência 2011. Os jovens do Brasil. Brasília. Instituto Sangari. 2011.

BRASIL. Plano Nacional de Segurança Pública - PLANASP. Disponível em: <portal.mj.gov.br>. Acesso em: 4 jun. 2013.

DIAS, Reinaldo; MATOS, Fernanda. Políticas públicas: princípios, propósitos e processos. São Paulo: Atlas, 2012.

LOPES, E. Política e segurança pública: uma vontade de sujeição. Rio de Janeiro: Contraponto, 2009. 
MATLAND, Richard E. Synthesizing the Implementation Literature: The Ambiguity-Conflict Model Policy Implementation. Journal of Public Administration Research and Theory, v. 5, n. 2, p. 145-174, 1995.

MINAS GERAIS. Assembléia Legislativa de Minas Gerais (ALMG) - Parlamento Jovem de Minas. Políticas Públicas: $O$ que são, para que servem e como são construídas. Disponível em:

http://www.almg.gov.br/acompanhe/eventos/parlamentojovem/2011/materialref erencia.html. 2011.

OLIVEIRA, André Luiz Dias de. Fatores condicionantes do processo de implementação de políticas públicas e como se relacionam com a variação de desempenho: um estudo comparativo no contexto do Programa Luz para Todos. 2012. 254 f. Dissertação (Mestrado em Administração) Universidade de Brasília, Brasília, 2012.

PEDRAZZINI, Yves. A violência das Cidades. Petrópolis: Vozes, 2006.

SARAIVA, Henrique. Introdução à Teoria da Política Pública. In. SARAIVA, Henrique; FERRAREZI, Elizabete (Orgs.). Coletânea Políticas Públicas. Brasília: ENAP, v. 1, p. 21-42, 2006.

SECCHI, Leonardo. Políticas públicas: conceitos, esquemas de análise, casos práticos. São Paulo: Cengage Learning, 2010.

SECCHI. Políticas públicas: conceitos, esquemas de análise, casos práticos. $2^{a}$ ed. São Paulo: Cengage Learning, 2013.

SILVA, Pedro Luis Barros; MELO, Marcos André Barreto. O processo de implementação de políticas públicas no Brasil: características e determinantes de avaliação de programas e projetos. Cadernos de Pesquisa, $\mathrm{n}^{\circ}$ 48, NEPP, UNICAMP, Campinas, 2000. 